\title{
Ministry of Health Clinical Practice Guidelines: Chronic Obstructive Pulmonary Disease
}

\author{
Tow Keang Lim, Cynthia Chee, Patsy Chow, Gerald Chua, Soo Kiang Eng, Soon Keng Goh, Kwee Keng Kng, \\ Wai Hing Lim, Tze Pin Ng, Thun How Ong, Angeline Seah, Hsien Yung David Tan, Augustine $\underline{\text { Tee }}$,
}

Vimal Palanichamy, Meredith Yeung

\begin{abstract}
The Ministry of Health ( $\mathrm{MOH})$ has updated the Clinical Practice Guidelines on Chronic Obstructive Pulmonary Disease (COPD) to provide doctors and patients in Singapore with evidence-based treatment for COPD. This article reproduces the introduction and executive summary (with recommendations from the guidelines) from the $\mathrm{MOH}$ Clinical Practice Guidelines on COPD, for the information of SMJ readers. Chapters and page numbers mentioned in the reproduced extract refer to the full text of the guidelines, which are available from the Ministry of Health website: https://www.moh. gov.sg/content/moh_web/healthprofessionalsportal/doctors/guidelines/cpg_medical.html. The recommendations should be used with reference to the full text of the guidelines. Following this article are multiple choice questions based on the full text of the guidelines.
\end{abstract}

\subsection{Objectives and scope of guideline}

These guidelines provide an update on the management of chronic obstructive pulmonary disease (COPD) in Singapore and take into account the new evidence which has emerged since the publication of the previous guidelines in 2006 .

\subsection{Target group}

The guidelines are intended for all healthcare professionals who care for patients with COPD. These include physicians, nurses, pharmacists, and rehabilitation and respiratory therapists.

\subsection{Guideline development}

These guidelines have been produced by a committee comprising senior respiratory physicians, general practitioners, polyclinic physicians, pharmacists, physiotherapists and a patient representative, appointed by the Ministry of Health $(\mathrm{MOH})$. They were developed using the best available current evidence and expert opinion.

\subsection{What is new in the revised guidelines}

The following is a list of major revisions or additions to the guidelines: (1) a template for the combined assessment of COPD; (2) a simplified COPD quality of life test: the COPD Assessment Test (CAT) score; (3) recommendations on pharmacological treatment based on results from recent clinical trials; and (4) a chapter on community care and comorbidities.

\subsection{Review of guidelines}

Evidence-based clinical practice guidelines are only as current as the evidence that supports them. Users must keep in mind that new evidence could supersede recommendations in these guidelines. The workgroup advises that these guidelines be scheduled for review five years after publication or if new evidence appears that requires substantive changes to the recommendations.

\section{EXECUTIVE SUMMARY OF RECOMMENDATIONS \\ Introduction}

This is the executive summary of the $\mathrm{MOH}$ Clinical Practice Guidelines (CPG) on COPD. It is intended to be used with reference to the full version of the $\mathrm{CPG}$, which is freely available on the $\mathrm{MOH}$ website at this link: http://www.moh.gov.sg/ content/moh_web/healthprofessionalsportal/doctors/guidelines/ cpg_medical.html.

COPD is a major cause of morbidity and mortality worldwide. In Singapore, COPD was the tenth leading cause of death in 2014.

\section{Target audience}

The guidelines are intended for all healthcare professionals who care for patients with COPD. These include physicians, nurses, pharmacists, and rehabilitation and respiratory therapists.

\section{How to use this document}

All recommendations made in the CPG are summarised in this document. Please note the following: (a) The page numbers of the full CPG document where each recommendation is explained are provided. (b) Each recommendation has a corresponding Grade of Recommendation and Level of Evidence (refer to Appendix for details). Key recommendations are highlighted in grey. 


\section{Commonly used abbreviations}

The following is a list of abbreviations commonly used in this set of guidelines (arranged in alphabetical order), and a description of what they represent.

\begin{tabular}{|c|c|}
\hline \multicolumn{2}{|c|}{ Commonly used abbreviations } \\
\hline CAT & COPD assessment test \\
\hline COPD & chronic obstructive pulmonary disease \\
\hline $\mathrm{FEV}_{1}$ & forced expiratory volume in one second \\
\hline$\Delta \mathrm{FEV}_{1}$ & change in $\mathrm{FEV}_{1}$ (difference between \\
\hline & post-bronchodilator and pre-bronchodilator $\mathrm{FEV}_{1}$ ) \\
\hline $\mathrm{FEV}_{1} / \mathrm{FVC}$ & forced expiratory ratio \\
\hline FVC & $\begin{array}{l}\text { forced vital capacity (volume of lungs from full } \\
\text { inspiration to forced maximal expiration) }\end{array}$ \\
\hline GOLD & Global Initiative for Chronic Obstructive Lung Disease \\
\hline ICS & inhaled corticosteroid \\
\hline LABA & long-acting beta ${ }_{2}$ agonist \\
\hline LAMA & long-acting muscarinic receptor antagonist \\
\hline $\mathrm{PaO}_{2}$ & partial pressure arterial oxygen \\
\hline PEF & peak expiratory flow \\
\hline SABA & short-acting beta ${ }_{2}$ agonist \\
\hline SAMA & short-acting muscarinic receptor antagonist \\
\hline
\end{tabular}

The following flowchart illustrates the treatment algorithm for a suspected case of COPD (page numbers are from the full CPG).

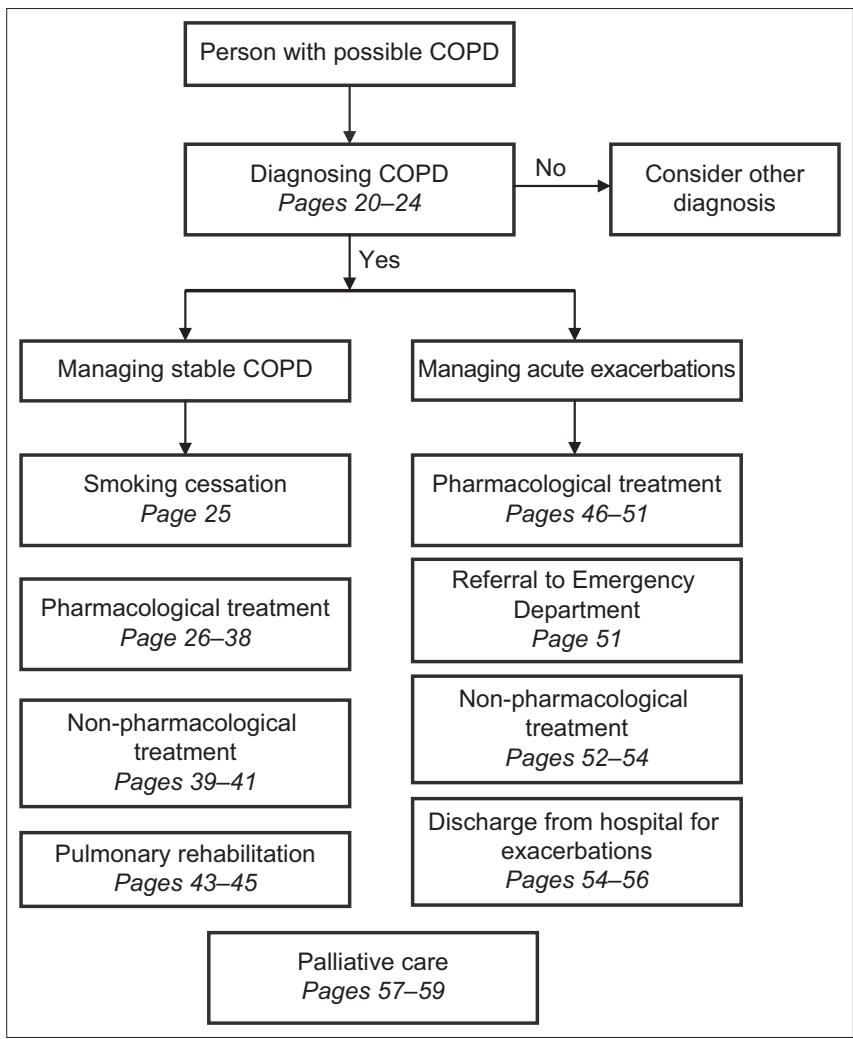

\section{Population prevalence $\&$ risk factors of COPD}

The Burden of Obstructive Lung Disease (BOLD) studies showed COPD among adults aged 40 and above varied widely among 12 countries, ranging from $11.4 \%$ to $26.1 \%$. Although the higher prevalence of COPD among smokers than non-smokers is well established, it is important to note that about $3 \%-10 \%$ of non-smokers also have COPD, indicating that non-smoking risk factors are also important.
Non-smoker risk factors include the use of biomass fuel, occupational exposure to dusts and gases, history of pulmonary tuberculosis, chronic asthma, respiratory tract infections during childhood, outdoor air pollution and poor socioeconomic status. Data from the Singapore Longitudinal Ageing Studies show similar prevalence and pattern of risk factors. The prevalence of COPD shows no gender differences, but is higher among older people and among smokers.

\section{Assessing and monitoring COPD Diagnosis of COPD}

The characteristic symptoms of COPD are persistent and progressive exertional dyspnoea, cough, sputum production, wheezing, and chest tightness that can vary from day to day. There should be a positive history of exposure to risk factors of tobacco smoke, smoke from home cooking and occupational dust.

Patients who are older than 40 years of age and who are current or ex-smokers should undertake spirometry if they answer 'yes' to any one of the following questions:

1. Do you cough regularly?

2. Do you cough up phlegm regularly?

3. Do even simple chores or light exertion make you short of breath?

4. Do you wheeze when you exert yourself, or at night?

5. Do you get frequent 'colds' that persist longer than those of other people you know?

(CPG pg. 20)

\section{All patients who are suspected to have COPD based on symptoms must be evaluated by spirometry. \\ (Grade D, Level 4, CPG pg. 20)}

A $\mathrm{FEV}_{1} / \mathrm{FVC}$ ratio $<0.7$ and a $\Delta \mathrm{FEV}_{1}<200 \mathrm{~mL}$ after bronchodilators treatment demonstrates expiratory airflow limitation. Such a result combined with the presence of characteristic symptoms and positive risk factor exposure is highly suggestive of COPD.

\section{Assessment of COPD}

Clinical assessment of the COPD patient should include a thorough history (i.e. occupational or environmental exposure to lung irritants, COPD signs and symptoms, complications, exacerbations) and physical examination.

The goals of COPD assessment are to determine disease severity, its impact on the patient's health status and the risk of future events such as exacerbations, hospitalisations or death in order to guide treatment.

A combined approach to COPD assessment considers the following aspects of the disease (Fig. 1): (1) current level of symptoms; (2) degree of $\mathrm{FEV}_{1}$ reduction; and (3) recent exacerbation profile.

D COPD patients should be classified into Group A, $\mathrm{B}, \mathrm{C}$ and $\mathrm{D}$ using the combined COPD assessment 


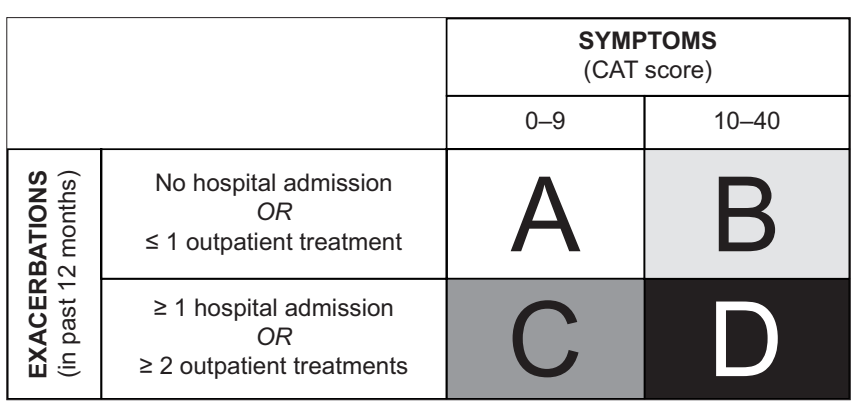

Fig. 1 Combined COPD assessment framework: Groups ABCD.

framework in accordance with GOLD 2017 guidelines.

(Grade D, Level 4, CPG pg. 22)

D

COPD symptoms should be quantified using the CAT score upon diagnosis and repeated every 3-6 months during follow-up.

(Grade D, Level 4, CPG pg. 21)

The CAT instrument can be found at http://www.catestonline. org/. Due to copyright restrictions, the CAT instrument cannot be reproduced.

The exacerbation history is crucial to the proper classification of COPD patients, and hence should be carefully elucidated.

(CPG pg. 21)

Assessment of comorbidities should be performed for patients diagnosed with COPD.

(CPG pg. 23)

D All patients with a history of COPD should be screened for cardiovascular risk factors.

(Grade D, Level 4, CPG pg. 43)

COPD often coexists with other diseases that may have a significant impact on prognosis. The presence of comorbidities should not alter COPD treatment, and comorbidities should be treated as if the patient did not have COPD.

\section{Role of chest $X$-ray}

Chest $X$-rays are not diagnostic of COPD but are valuable in assessing comorbidities and excluding conditions, such as lung cancer and pulmonary tuberculosis - symptoms of which are similar to that of COPD.

D A chest X-ray should be done when a diagnosis of COPD is suspected.

(Grade D, Level 4, CPG pg. 23)

\section{Monitoring of COPD}

GPP COPD patients should be followed up every 3-6 months. The CAT score should be used at each visit to track symptoms related to COPD. Routine yearly chest X-rays are not required.

(CPG pg. 24)

If a patient reports acute or progressive worsening of respiratory symptoms, the following possibilities will need to be considered: (1) The patient is experiencing a COPD exacerbation. (2) The COPD severity is worsening. (3) There is a superimposed acute/subacute respiratory condition, e.g. pneumonia, pneumothorax, pulmonary tuberculosis (PTB), lung cancer. (4) The comorbid conditions, e.g. ischaemic heart disease (IHD) and heart failure, are unstable.

\section{Smoking cessation}

A Smoking cessation is a vital intervention in COPD which will preserve lung function and improve survival. It is recommended for all patients with COPD.

(Grade A, Level 1+, CPG pg. 25)

\section{Pharmacological treatment}

The goals of pharmacotherapy in COPD are as follows: (1) Relieve, reduce and abolish symptoms where possible. (2) Increase exercise capacity. (3) Reduce frequency and severity of acute exacerbations. (4) Improve health related quality of life.

The principles of therapy in COPD are as follows: (1) Treatment needs to be maintained long-term. (2) Treatment needs to be tailored according to severity of airway obstruction and symptoms, as well as risk of exacerbations, with step-wise increase usually required. (3) Attention should be given to the route of administration, especially via inhalational route.

When treatment is given via inhalational route, choice of device will depend on availability, cost and patient's ability. Use of a spacer with metered dose inhaler devices may overcome coordination problems and improve drug delivery.

\section{Bronchodilators}

In choosing among treatment options for patients, decisionmaking can be guided by choosing the appropriate drug class according to GOLD guidelines.

A Short-acting bronchodilators are prescribed on an asneeded basis and should be the initial empirical treatment for the relief of breathlessness and exercise limitation.

(Grade A, Level $1^{+}$, CPG pg. 27)

A Patients with persistent breathlessness (GOLD Group B) should receive a $L A B A$ or a $L A M A$. If a $L A M A$ is started, SAMA (including nebulisations) should be stopped. Patients with persistent breathlessness should be escalated to a LABA/LAMA combination.

(Grade A, Level 1+, CPG pg. 31)

A Patients with minimal symptoms but frequent exacerbations (GOLD Group C) should receive a LAMA as first-line treatment. If further exacerbations 
occur, treatment should preferably be escalated to a LAMA/LABA combination; a LABA/ICS combination can also be used. Patients with persistent symptoms and frequent exacerbations (GOLD Group D) should be started first on a LABA/LAMA combination.

(Grade A, Level 1+, CPG pg. 31)

\section{Steroids}

A Addition of ICS to standard therapy should be considered for patients with moderate to severe COPD (GOLD Group C and D) with frequent exacerbations. The expected benefit of reduction in exacerbations should be balanced against risk of pneumonia. Stand-alone ICS is not recommended for COPD patients.

(Grade A, Level 1+, CPG pg. 32)

A Combination of ICS and LABA in one inhaler should be considered for patients in whom both ICS and LABA are indicated.

(Grade A, Level 1+, CPG pg. 33)

A For patients with frequent exacerbations ( $\geq 2$ per year) and persistent breathlessness with $\mathrm{FEV}_{1}<50 \%$ of predicted (GOLD Group $C$ and D), the use of combination therapy (LABA/ICS or LABA/LAMA) is recommended.

(Grade A, Level 1+, CPG pg. 32)

A Long-term oral steroids are discouraged in view of unfavourable risk-benefit ratio.

(Grade A, Level 1+, CPG pg. 33)

\section{Methylxanthines}

D Low-dose theophylline may be considered in patients with COPD where symptom control is still not achieved with existing inhaled bronchodilator therapy.

(Grade D, Level 4, CPG pg. 35)

However, careful monitoring for side effects and drug interactions is needed in view of its narrow therapeutic index. Table 1 lists the factors/drugs which may precipitate drug toxicity.

Addition of roflumilast to inhaled bronchodilator therapy may provide benefits in reducing exacerbations in patients with $\mathrm{FEV}_{1}<50 \%$ and chronic bronchitis who have recurrent exacerbations despite triple inhaler therapy. However, this must be weighed in the context of increased risk of adverse events.

(Grade B, Level 1-', CPG pg. 36)

\section{Long-term macrolides}

B Long-term macrolide treatment (6-12 months) may be considered in a select group of patients who have
Table 1. Drugs and physiological variables that affect theophylline metabolism in COPD.

\begin{tabular}{|l|l|}
\hline Increased clearance & Decreased clearance \\
\hline 1. Cigarette smoking & 1. Old age \\
2. Anticonvulsant drugs & 2. Hypoxaemia \\
4. Alcohol & 3. Respiratory acidosis \\
& 4. Congestive cardiac failure \\
& 5. Liver cirrhosis \\
& 6. Erythromycin, clarithromycin \\
& 7. Quinolones \\
& 8. Cimetidine (not ranitidine) \\
& 9. Antifungals \\
& 10. Fluoxetine, fluvoxamine, sertraline \\
& 11. Viral infections \\
& 12. Some herbal remedies
\end{tabular}

multiple exacerbations which are refractory to standard therapy. There is insufficient data to recommend routine use of macrolides in the treatment of COPD.

(Grade B, Level 1+, CPG pg. 36)

\section{Mucolytics}

B Mucolytic drug therapy should be considered in patients with a chronic cough productive of sputum, and should be continued if there is symptomatic improvement.

(Grade B, Level 1+, CPG pg. 37)

\section{Escalation and de-escalation of therapy}

In patients who are persistently symptomatic or who have recurrent exacerbations, care should be taken to evaluate compliance, check inhaler technique, and exclude other concomitant pathology and comorbidity (e.g. a COPD patient may also be suffering from ischaemic heart disease and congestive cardiac failure, or may have lung cancer or tuberculosis). If these are excluded, treatment of the COPD needs to be optimised.

A suggested algorithm for initiation and escalation of pharmacological treatment of stable COPD is presented in Fig. 2.

\section{Non-pharmacological treatment \\ Long-term oxygen therapy}

A Long-term oxygen therapy is indicated in patients with severe COPD who are in chronic respiratory failure (blood oxygen saturation $\left[\mathrm{SpO}_{2}\right] \leq 88 \%$ ).

(Grade A, Level 1+, CPG pg. 39)

\section{Surgical treatments}

A Lung volume reduction surgery is indicated in selected patients with upper lobe emphysema and poor exercise capacity after rehabilitation.

(Grade A, Level 1+, CPG pg. 39) 


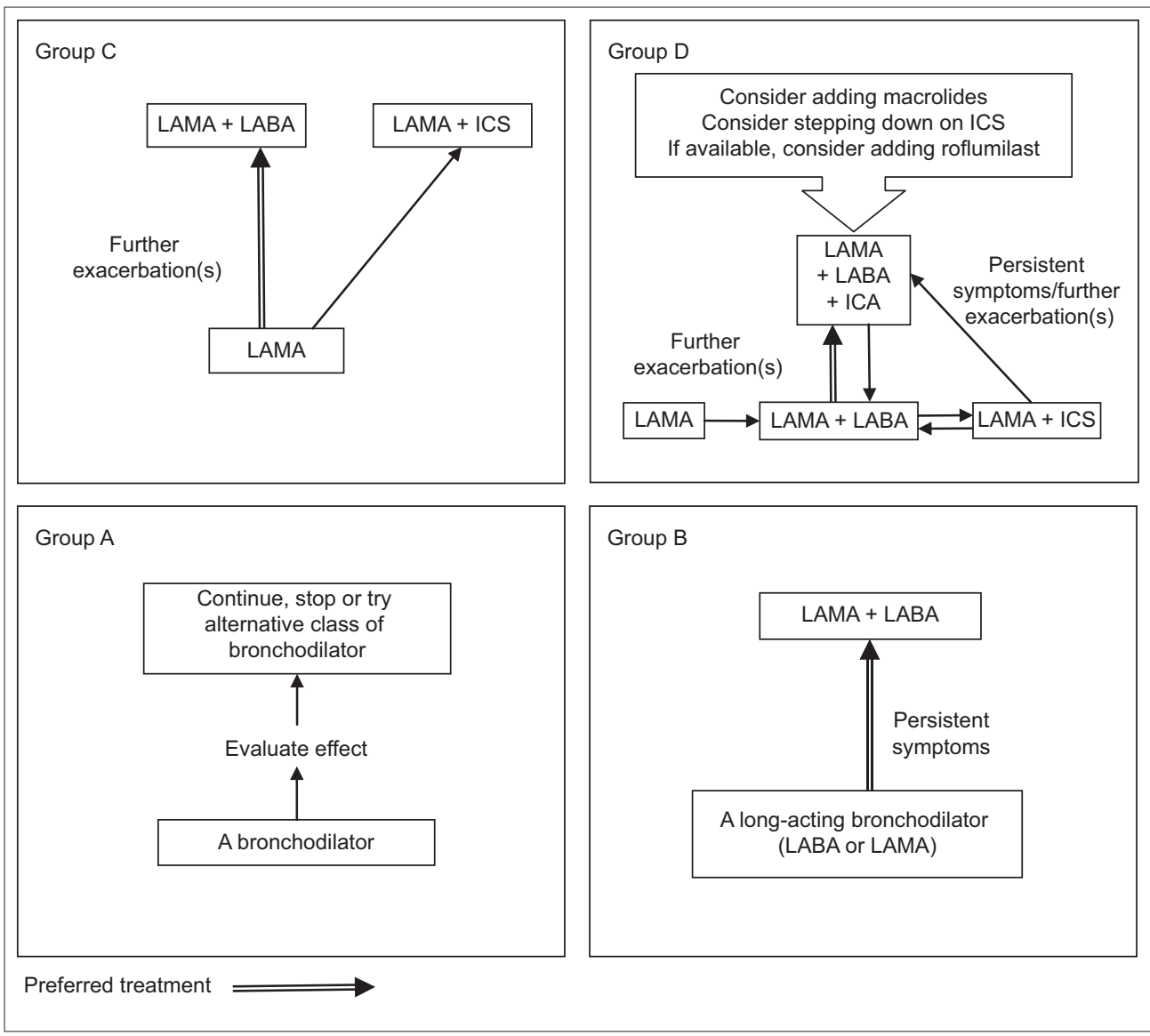

Fig. 2 Suggested algorithm for management and escalation of treatment in COPD (modified from GOLD 2017 Figure 4.1).

D Bullectomy may be beneficial in selected COPD patients with bullae occupying more than one-third of the hemithorax.

(Grade D, Level 3, CPG pg. 40)

A Bronchoscopic lung volume reduction treatment may have a role only in carefully selected COPD patients.

(Grade A, Level $1^{+}$, CPG pg. 40)

D Lung transplantation may be indicated in selected patients with advanced COPD.

(Grade D, Level 3, CPG pg. 40)

\section{Vaccinations}

A COPD patients should be offered annual vaccination with the seasonal inactivated influenza vaccine.

(Grade A, Level 1+, CPG pg. 41)

C Pneumococcal vaccination should be considered in COPD patients.

(Grade C, Level 2+, CPG pg. 41)

\section{Screening in the community}

GPP All patients $\geq 40$ years of age with a history of smoking should be assessed on a yearly basis for symptoms of
COPD, i.e. dyspnoea, chronic cough or chronic sputum production.

(CPG pg. 42)

D Patients with any symptoms of COPD (i.e. dyspnoea, chronic cough or chronic sputum production) should undergo spirometry to assess for the presence of COPD.

(Grade D, Level 4, CPG pg. 42)

D Screening spirometry in the general asymptomatic population is not recommended.

(Grade D, Level 4, CPG pg. 42)

GPP Where practicable, general practitioners should arrange for their patients to undergo spirometry to help in the diagnosis of COPD in the community as a standard practice.

(CPG pg. 43)

D Personnel conducting spirometry testing should be trained in the conduct of the test and be familiar with the machines they are using.

(Grade D, Level 4, CPG pg. 43)

D Spirometries should be undertaken when patients are clinically stable and free from respiratory tract infections.

(Grade D, Level 4, CPG pg. 43) 


\section{Management of acute exacerbations}

An exacerbation is a sustained worsening of the patient's symptoms from their usual stable state which is beyond normal day-to-day variations, and is acute in onset. Exacerbations are defined as mild when there is a change of inhaled treatment by the patient, moderate when exacerbations of respiratory symptoms require medical intervention including a short course of antibiotic and/or oral steroids, and severe when exacerbations of respiratory symptoms require hospitalisation.

The diagnosis of an exacerbation is made clinically and does not depend on the results of investigations. The goals of treatment for an acute exacerbation of COPD are to minimise the impact of the current exacerbation and prevent the development of subsequent exacerbations.

D Sending sputum samples for culture in primary care is not recommended.

(Grade D, Level 4, CPG pg. 47)

D Spirometric tests are not recommended during an exacerbation of COPD.

(Grade D, Level 4, CPG pg. 47)

C In all patients with an exacerbation referred to hospital, a chest radiograph should be obtained and is useful in excluding alternative diagnoses.

(Grade C, Level 2+, CPG pg. 47)

B Measuring arterial blood gas tensions should be considered and the inspired oxygen concentration should be recorded.

(Grade B, Level 2++, CPG pg. 47)

D Theophylline level should be measured in patients on theophylline therapy at admission to rule out toxicity.

(Grade D, Level 4, CPG pg. 47)

The management algorithm for an acute exacerbation is described in Fig. 3.

\section{Pharmacological management of an acute exacerbation} Bronchodilators

C Inhaled SABAs with or without inhaled SAMA are the preferred bronchodilators for treatment of an exacerbation of COPD.

(Grade C, Level 2+, CPG pg. 49)

A Both nebulisers and hand-held inhalers can be used to administer inhaled therapy during exacerbations of COPD.

(Grade A, Level $1^{+}$, CPG pg. 49)

D Patients should be changed to hand-held inhalers as soon as their condition has stabilised.

(Grade D, Level 4, CPG pg. 49)

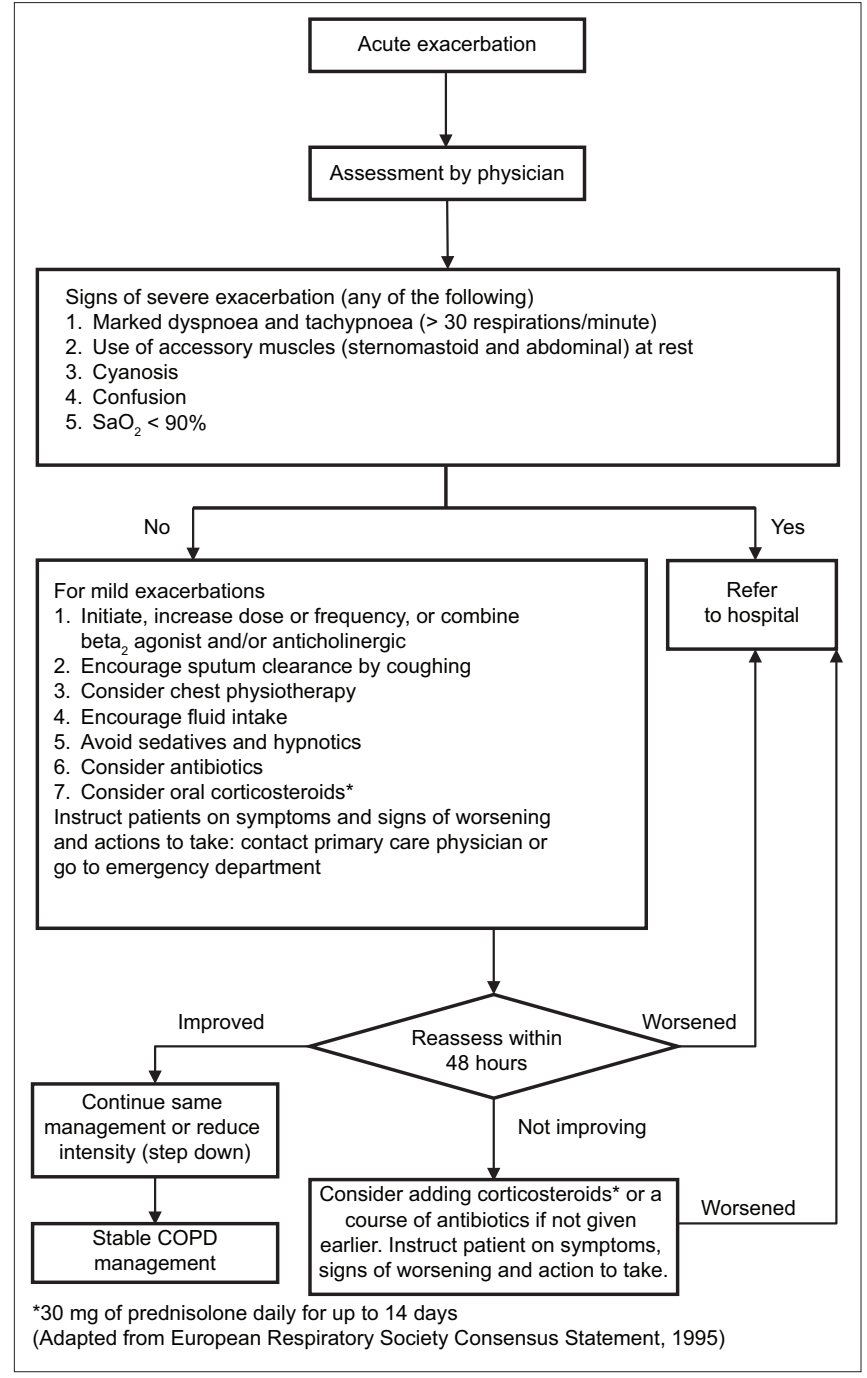

Fig. 3 Algorithm for the management of an acute exacerbation.

A If a patient is hypercapnic or acidotic, the nebuliser should be driven by compressed air, not oxygen (to avoid worsening hypercapnia). If oxygen therapy is needed, it should be administered simultaneously by nasal cannulae.

(Grade A, Level 1+, CPG pg. 49)

\section{Systemic corticosteroids}

A Systemic corticosteroids should be used in conjunction with other therapies in all patients admitted to hospital with an exacerbation of COPD.

(Grade A, Level 1+, CPG pg. 50)

A In the absence of significant contraindications, oral corticosteroids should be considered in patients in the community who have an exacerbation with a significant increase in breathlessness which interferes with daily activities.

(Grade A, Level 1+, CPG pg. 50)

A For COPD patients with acute exacerbation, prednisolone $30 \mathrm{mg}$ orally should be administered for 5-10 days. 
There is no added clinical benefit of duration of systemic corticosteroids beyond 14 days.

(Grade A, Level 1+, CPG pg. 50)

\section{Antibiotics}

A Antibiotics should be used to treat exacerbations of COPD associated with a history of more purulent sputum.

(Grade A, Level 1+, CPG pg. 50)

A Antibiotics should be given in exacerbations of COPD if the patient requires mechanical ventilation (invasive or non-invasive).

(Grade A, Level 1+, CPG pg. 50)

A

The length of antibiotic therapy need not exceed five days for mild to moderate exacerbations of COPD.

(Grade A, Level 1+, CPG pg. 51)

A

For moderate to severe exacerbations of COPD, a 7-10 day course of antibiotics is recommended.

(Grade A, Level $1^{+}$, CPG pg. 51)

\section{Referral to emergency department}

The majority of patients with COPD exacerbations can be successfully managed as outpatients. The indications for hospital assessment and factors which determine site of care are listed in Table 2.

GPP Table 2. Indications for hospital assessment or admission (CPG pg. 51).

No. Indications

1 Marked increase in intensity of symptoms, such as sudden development of resting dyspnoea

2 Severe underlying COPD

3 Onset of new physical signs (e.g. cyanosis, peripheral oedema)

$4 \quad$ Failure of an exacerbation to respond to initial medical management

$5 \quad$ Presence of serious comorbidities (e.g. heart failure or newly occurring arrhythmias)

\begin{tabular}{l|l}
\hline 6 & Frequent exacerbations
\end{tabular}

$7 \quad$ Older age

8 Insufficient home support

\section{Non-pharmacological therapy}

Controlled oxygen therapy

A For COPD patients with acute exacerbation, controlled oxygen should be given to keep the blood oxygen saturation $\left(\mathrm{SaO}_{2}\right)$ within a target saturation of $88 \%-92 \%$.

(Grade A, Level 1+, CPG pg. 52)

Patients with severe exacerbations who fail to respond to oxygen and pharmacotherapy may need ventilator support, which may be invasive or non-invasive. Mechanical ventilation should be performed in a setting with local expertise such as an intensive care unit (ICU). The indications for admission to ICU are listed in Table 3.

D Table 3. Indications for ICU admission (Grade D, Level 4, CPG pg. 52).

\begin{tabular}{|l|l|}
\hline No. & Indications \\
\hline 1 & $\begin{array}{l}\text { Severe dyspnoea that responds inadequately to initial } \\
\text { emergency therapy. }\end{array}$ \\
\hline 2 & Changes in mental status (confusion, lethargy, coma). \\
\hline 3 & $\begin{array}{l}\text { Persistent or worsening hypoxaemia }\left(\mathrm{PaO}_{2}<40 \mathrm{mmHg}\right) \\
\text { and/or severe worsening respiratory acidosis }(\mathrm{pH}<7.25) \\
\text { despite supplemental oxygen and non-invasive ventilation. }\end{array}$ \\
\hline 4 & Need for invasive mechanical ventilation. \\
\hline 5 & $\begin{array}{l}\text { Haemodynamically unstable COPD patients who need } \\
\text { vasopressors. }\end{array}$ \\
\hline
\end{tabular}

Non-invasive ventilation

A Non-invasive ventilation should be used as the treatment of choice for persistent hypercapnic ventilatory failure during exacerbations of COPD despite optimal medical therapy.

(Grade A, Level $1^{++}$, CPG pg. 53)

D When patients are started on non-invasive ventilation, there should be a clear plan covering what to do in the event of deterioration and ceilings of therapy should be agreed. (Grade D, Level 4, CPG pg. 53)

A Table 4. Indications for non-invasive mechanical ventilations (Grade A, Level $1^{++}$, CPG pg. 53).

\begin{tabular}{|l|l|}
\hline No. & Indications $(\geq \mathbf{1}$ of the following) \\
\hline 1 & $\begin{array}{l}\text { Respiratory acidosis (arterial } \mathrm{pH}<7.35 \text { and/or } \\
\left.\mathrm{PaCO}_{2}>45 \mathrm{mmHg}\right)\end{array}$ \\
\hline 2 & Severe dyspnoea \\
\hline
\end{tabular}

Invasive ventilation

D Table 5. Indications for invasive mechanical ventilations (Grade D, Level 4, CPG pg. 54).

\begin{tabular}{|l|l|}
\hline No. & Indications \\
\hline 1 & $\begin{array}{l}\text { Unable to tolerate non-invasive ventilation or non-invasive } \\
\text { ventilation failure }\end{array}$ \\
\hline 2 & Respiratory or cardiac arrest \\
\hline 3 & $\begin{array}{l}\text { Respiratory pauses with loss of consciousness or gasping } \\
\text { for air }\end{array}$ \\
\hline 4 & $\begin{array}{l}\text { Diminished consciousness, psychomotor agitation } \\
\text { inadequately controlled by sedation }\end{array}$ \\
\hline 5 & Massive aspiration \\
\hline 6 & Persistent inability to remove respiratory secretions \\
\hline 7 & Heart rate < 50/minute with loss of alertness \\
\hline 8 & $\begin{array}{l}\text { Severe haemodynamic instability without response to } \\
\text { fluids and vasoactive drugs }\end{array}$ \\
\hline 9 & Severe ventricular arrhythmias \\
\hline 10 & $\begin{array}{l}\text { Life-threatening hypoxaemia in patients unable to tolerate } \\
\text { non-invasive ventilation }\end{array}$ \\
\hline
\end{tabular}


Non-invasive ventilation should be used to facilitate liberation from invasive ventilation in patients recovering from an exacerbation of COPD but who fail spontaneous breathing trials.

(Grade A, Level 1+, CPG pg. 54)

\section{Pulmonary rehabilitation}

Pulmonary rehabilitation forms an important component of the management of COPD following exacerbations.

Inpatient pulmonary rehabilitation should be started once the patient is medically stable after acute exacerbation of COPD.

(Grade A, Level $1^{++}$, CPG pg. 45)

\section{Discharge from hospitalisation for exacerbations}

D Patients should be re-established on their optimal maintenance bronchodilator therapy before discharge. (Grade D, Level 4, CPG pg. 54)

Patients who have had an episode of respiratory failure should have satisfactory oximetry or arterial blood gas results before discharge. If peripheral saturation is $<92 \%$, arterial blood gases should be assessed.

(Grade D, Level 4, CPG pg. 55

D All aspects of the routine care that patients receive (including appropriateness and risk of side effects) should be assessed before discharge.

(Grade D, Level 4, CPG pg. 55)

D Patients (or home carers) should be given appropriate information to enable them to fully understand the correct use of medications, including oxygen, before discharge.

(Grade D, Level 4, CPG pg. 55

D Arrangements for follow-up and home care (such as visiting nurse, oxygen delivery, referral for other support) should be made before discharge.

(Grade D, Level 4, CPG pg. 55)

A Hospital-at-home and assisted-discharge schemes are safe and effective, and should be used as an alternative way of caring for patients with exacerbations of COPD who would otherwise need to be admitted or stay in hospital.

(Grade A, Level 1+, CPG pg. 55)
D Clinicians who care for patients with chronic or advanced respiratory diseases should be trained in and be capable of providing basic palliative care to prevent and relieve suffering by controlling symptoms.

(Grade D, Level 4, CPG pg. 57)

D Clinicians should consult with palliative care specialists as appropriate for managing palliative care situations beyond their level of competence.

(Grade D, Level 4, CPG pg. 57)

\section{Advance Care Planning}

D COPD patients with two or more of the following criteria are candidates for end-of-life discussion and Advance Care Planning:

- $\mathrm{FEV}_{1} \leq 30 \%$

- Starting on long-term oxygen therapy

- Repeated admissions for COPD exacerbation

- Unintended progressive weight loss or cachexia

- Functional decline

- Development of significant comorbidities

- A positive answer to the 'surprise' question: 'Will you be surprised if your patient dies in the next one year?'

- Lack of additional treatment options

(Grade D, Level 4, CPG pg. 58)

\section{Symptom management}

D Opioids (oral or parenteral) are effective therapy for the management of refractory dyspnoea and should be considered on an individual basis.

(Grade D, Level 4, CPG pg. 59)

D Anxiety and depression accompany dyspnoea and should be evaluated and treated accordingly. Benzodiazepines, tricyclic anti-depressants and major tranquilisers may be useful in this context.

(Grade D, Level 4, CPG pg. 59)

B Oxygen and fans blowing air onto the face can relieve breathlessness.

(Grade B, Level 2++, CPG pg. 59)

A Fatigue can be improved by self-management education, pulmonary rehabilitation and mind-body interventions.

(Grade A, Level 2++, CPG pg. 59)

\section{Clinical quality improvement}

The following clinical quality indicators are recommended. Healthcare providers may use these indicators to monitor their practice and to better gauge their quality of care. 


\begin{tabular}{|l|l|l|}
\hline $\begin{array}{l}\text { Quality } \\
\text { indicators }\end{array}$ & $\begin{array}{l}\text { Recommended } \\
\text { minimum } \\
\text { frequency* }\end{array}$ & $\begin{array}{l}\text { Examples of suggested } \\
\text { measurable indicators }\end{array}$ \\
\hline Smoking & Annual & $\begin{array}{l}\text { Percentage of COPD patients } \\
\text { whose smoking habits and } \\
\text { desire to quit were assessed } \\
\text { on one occasion in the past } \\
\text { one year (except for those who } \\
\text { have never smoked, where } \\
\text { smoking habits should be } \\
\text { recorded once) }\end{array}$ \\
\hline $\begin{array}{l}\text { Inhaler } \\
\text { technique }\end{array}$ & Annual & $\begin{array}{l}\text { Percentage of COPD patients } \\
\text { who have a record of inhaler } \\
\text { technique assessment in the } \\
\text { past one year }\end{array}$ \\
\hline $\begin{array}{l}\text { Influenza } \\
\text { vaccination }\end{array}$ & Annual & $\begin{array}{l}\text { Percentage of COPD patients } \\
\text { who have a record of influenza } \\
\text { vaccination being offered in } \\
\text { the past one year }\end{array}$ \\
\hline
\end{tabular}

*Users may consider allowing an added margin of time (e.g. additional three months) when assessing adherence to recommended annual frequencies. 


\section{APPENDIX}

\section{Levels of evidence and grades of recommendations}

\begin{tabular}{|c|c|}
\hline Level & Type of Evidence \\
\hline $1^{++}$ & $\begin{array}{l}\text { High quality meta-analyses, systematic reviews of randomised controlled trials (RCTs), or RCTs with a very low risk } \\
\text { of bias }\end{array}$ \\
\hline $1^{+}$ & Well conducted meta-analyses, systematic reviews of RCTs, or RCTs with a low risk of bias \\
\hline 1. & Meta-analyses, systematic reviews of RCTs, or RCTs with a high risk of bias \\
\hline $2^{++}$ & $\begin{array}{l}\text { High quality systematic reviews of case control or cohort studies. High quality case control or cohort studies with a } \\
\text { very low risk of confounding or bias and a high probability that the relationship is causal }\end{array}$ \\
\hline $2^{+}$ & $\begin{array}{l}\text { Well conducted case control or cohort studies with a low risk of confounding or bias and a moderate probability } \\
\text { that the relationship is causal }\end{array}$ \\
\hline 2 & $\begin{array}{l}\text { Case control or cohort studies with a high risk of confounding or bias and a significant risk that the relationship is } \\
\text { not causal }\end{array}$ \\
\hline 3 & Non-analytic studies, e.g. case reports, case series \\
\hline 4 & Expert opinion \\
\hline
\end{tabular}

\section{Grades of recommendation}

\begin{tabular}{ll}
\hline Grade & Recommendation \\
\hline A & At least one meta-analysis, systematic review of RCTs, or RCT rated as $1^{++}$and directly applicable to the target \\
& population; or \\
& A body of evidence consisting principally of studies rated as $1^{+}$, directly applicable to the target population, and \\
& demonstrating overall consistency of results \\
& A body of evidence including studies rated as $2^{++}$, directly applicable to the target population, and demonstrating \\
overall consistency of results; or \\
Extrapolated evidence from studies rated as $1^{++}$or $1^{+}$ \\
A body of evidence including studies rated as $2^{+}$, directly applicable to the target population and demonstrating \\
overall consistency of results; or \\
Extrapolated evidence from studies rated as $2^{++}$ \\
Evidence level 3 or $4 ;$ or \\
Extrapolated evidence from studies rated as $2^{+}$ \\
GPP (good
\end{tabular}




\section{SINGAPORE MEDICAL COUNCIL CATEGORY 3B CME PROGRAMME} (Code SMJ 201802B)

These questions are based on the full text of the guidelines which may be found at https://www.moh.gov.sg/content/moh_web/ healthprofessionalsportal/doctors/guidelines/cpg_medical.html.

Question 1. Regarding pharmacotherapy for stable chronic obstructive pulmonary disease (COPD):

(a) Tiotropium should not be combined with inhaled corticosteroids.

(b) Combination therapy comprising a long-acting beta ${ }_{2}$ agonist and long-acting muscarinic receptor antagonist is a treatment option for patients with persistent breathlessness.

(c) When a patient is prescribed with clarithromycin and theophylline, closer monitoring of side effects of theophylline is needed.

(d) Combination inhaled corticosteroids and long-acting bronchodilators are the first choice treatment for GOLD Group A patients.

Question 2. Pertaining to non-pharmacological treatment of COPD:

(a) Long-term oxygen therapy has been shown to improve survival in COPD patients with chronic respiratory failure.

(b) There is no evidence that lung volume reduction surgery improves quality of life and survival in patients with COPD.

(c) Annual influenza vaccination has been shown to significantly decrease COPD exacerbations due to influenza.

(d) Both the pneumococcal polysaccharide vaccine and polysaccharide conjugate vaccine are effective in preventing invasive pneumococcal disease in adults.

Question 3. With regard to pulmonary rehabilitation:

(a) $23 \%$ of COPD patients take up pulmonary rehabilitation in Singapore.

(b) Pulmonary rehabilitation should commence once the patient is medically stable after acute exacerbation of COPD.

(c) Pulmonary rehabilitation is ineffective in reducing anxiety, depression and psychological well-being.

(d) Pulmonary rehabilitation improves maximal exercise capacity and endurance, but has no impact on reducing acute exacerbation and hospitalisation.

Question 4. With regard to comorbidities:

(a) When treating COPD patients for hypertension, they have a higher blood pressure target as compared to non-COPD patients.

(b) Recurrent exacerbations in COPD patients could result in worsening diabetic control.

(c) COPD patients should undergo routine cardiovascular screening as part of their follow-up.

(d) COPD patients with diabetes have similar targets for control as patients without COPD.

Question 5. For patients with Stage D with persistent breathlessness:

(a) Advanced Care Planning should be initiated.

(b) Eliciting both the patient's and family's values, preferences and goals of care at the end of life is important.

(c) Opioids should not be used in patients suffering from refractory dyspnoea in advanced COPD, as they may further increase $\mathrm{PaCO}_{2}$.

(d) Management of the physical component of refractory dyspnoea takes precedence over management of the psychological aspect.

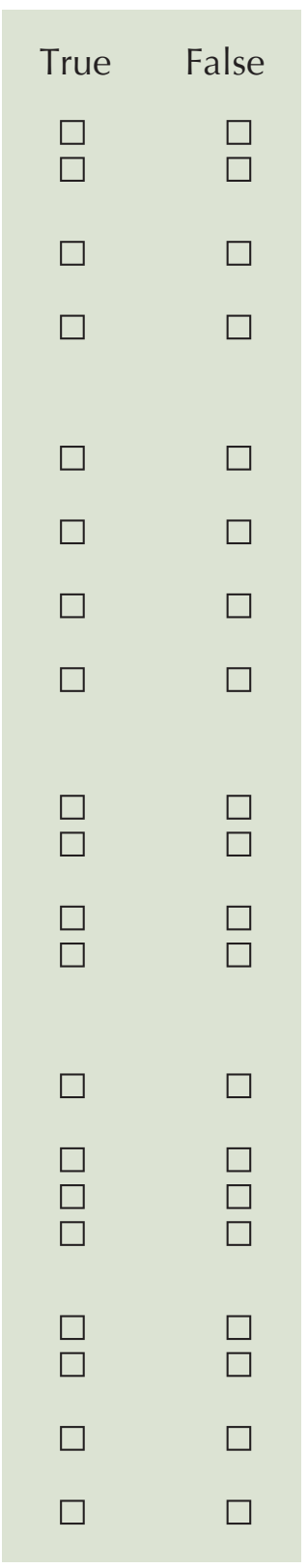

\section{Doctor's particulars:}

Name in full

MCR number

Specialty:

Email address

\section{SUBMISSION INSTRUCTIONS:}

Visit the SMJ website: http://www.smj.org.sg/current-issue and select the appropriate quiz. You will be redirected to the SMA login page.

For SMA member: (1) Log in with your username and password (if you do not know your password, please click on 'Forgot your password?'). (2) Select your answers for each quiz and click 'Submit'.

For non-SMA member: (1) Create an SMJ-CME account, or login with your SMJ-CME username and password (for returning users). (2) Make payment of SGD 21.40 (inclusive of $7 \%$ GST) via PayPal to access this month's quizzes. (3) Select your answers for each quiz and click 'Submit'.

RESULTS:

(1) Answers will be published online in the SMJ April 2018 issue. (2) The MCR numbers of successful candidates will be posted online at the SMJ website by 4 April 2018. (3) Passing mark is $60 \%$. No mark will be deducted for incorrect answers. (4) The SMJ editorial office will submit the list of successful candidates to the Singapore Medical Council. (5) One CME point is awarded for successful candidates. 